\title{
METHOD DEVELOPMENT AND VALIDATION OF SELECTIVE AND HIGHLY SENSITIVE METHOD FOR DETERMINATION OF APIXABAN IN HUMAN PLASMA USING LIQUID CHROMATOGRAPHY-TANDEM MASS SPECTROMETRY
}

\author{
CHAITANYA KRISHNA ATMAKURI ${ }^{1}{ }^{*}$, CHEEPURUPALLI PRASAD ${ }^{2}$, RAJARAM S. PATIL ${ }^{3}$, KARUNAKRANTH \\ DHARANI ${ }^{4}$
}

${ }^{1}$ Faculty of Pharmacy, Pacific Academy of Higher Education and Research University, Udaipur, Rajasthan, India, ${ }^{2}$ Vignan Institute of Pharmaceutical Technology, Visakhapatnam, India, ${ }^{3}$ Director, Omacon Analytical Solutions LLP, Thane, India, ${ }^{4}$ M. Pharm. Ph. D. Pharmaceutical Analysis, Mumbai, India Email: kriss.iway@gmail.com

Received: 05 May 2019 Revised and Accepted: 04 Jul 2019

\section{ABSTRACT}

Objective: The present research work aims to develop and validate a selective and highly sensitive method for the determination of apixaban in human plasma using liquid chromatography-tandem mass spectrometry (LC-MS/MS).

Methods: $200 \mu \mathrm{l}$ of sodium heparin plasma samples were acidified and clean-up was performed by using solid-phase extraction (SPE). Apixaban 13C D3 was used as an internal standard (deuterated) to lower the relative matrix effects and a single step SPE was employed for sample clean up. $10 \mu \mathrm{l}$ of SPE eluent was loaded onto Hypersil Beta Basic C18, 100×4.6 mm, $5 \mu$ column for highly selective chromatographic separation using an isocratic mobile phase. $2 \mathrm{mmol}$ ammonium acetate in water and acetonitrile were delivered by using a quaternary low-pressure gradient pump without premixing at a minimum flow rate of $0.50 \mathrm{ml} / \mathrm{min}$.

Results: LC-MS/MS method was successfully developed and validated to demonstrate the lowest detection limit of 0.05 ng/ml and a linear dynamic range from $1-250 \mathrm{ng} / \mathrm{ml}$ with $\mathrm{r}^{2}>0.99$. Method development and validation results proved that the method is selective and highly sensitive for the determination of apixaban in human plasma using LC-MS/MS.

Conclusion: Current method can be applied for both therapeutic drug monitoring (TDM) and pharmacokinetic (PK) study analysis.

Keywords: Human Plasma, Liquid Chromatography-Tandem, Mass spectrometry

(c) 2019 The Authors. Published by Innovare Academic Sciences Pvt Ltd. This is an open-access article under the CC BY license (http://creativecommons.org/licenses/by/4.0/) DOI: http://dx.doi.org/10.22159/ijpps.2019v11i8.33948

\section{INTRODUCTION}

Apixaban is a direct oral anticoagulant used in the management of thromboembolism and has gained importance as an alternative replacement to the vitamin $\mathrm{K}$ antagonists such as warfarin [1]. Therapeutic dose of apixaban results in nanogram level plasma concentrations. Therefore, it is evident to use a validated method for the estimation of apixaban in biological matrices like human plasma either for pharmacokinetic (PK) study analysis [2] or for therapeutic drug monitoring (TDM). LC-MS/MS is the only advanced technology that allows highly sensitive and selective-high throughput analysis even with low sample volumes. Moreover, it requires minimal and simple sample preparation procedures. Though several methods are available for determination of apixaban in human plasma or serum on LC-MS/MS [3-12], they were applied either for PK study analysis or for TDM but not for both. Therefore, the objective of the current study was to develop and validate a highly sensitive method with the lowest possible sample volumes, so that the same method can be further used for TDM also apart from PK study analysis.

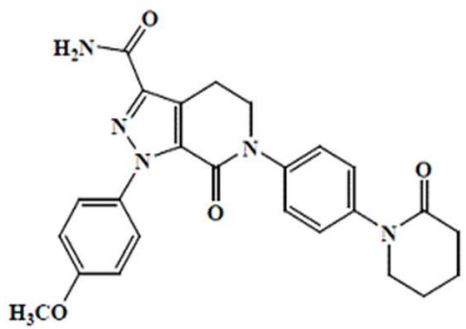

Fig. 1: Structure of apixaban
Apixaban is chemically described as 1-(4-methoxyphenyl)-7-oxo6-[4-(2-oxopiperidin-1-yl) phenyl]-4,5,6,7-tetrahydro-1H-pyrazolo $[3,4 c]$ pyridine-3-carboxamide. Its molecular formula is $\mathrm{C}_{25} \mathrm{H}_{25} \mathrm{~N}_{5} \mathrm{O}_{4}$, which corresponds to a molecular weight of 459.50. Apixaban has the following structural formula [13].

\section{MATERIALS AND METHODS}

Reagents and chemicals

Methanol (gradient grade), acetonitrile (gradient grade), orthophosphoric acid (guaranteed reagent grade) was purchased from Merck. Ammonium acetate (reagent grade) was purchased from Sigma Aldrich. Water (liquid chromatography-mass spectrometry grade) was used in-house from Milli Q system. Apixaban and apixaban 13C D3 were purchased from Vivan life sciences.

Preparation of standard solutions and quality control samples

Standard solutions of apixaban $(100 \mu \mathrm{g} / \mathrm{ml})$ and apixaban 13C D3 $(100 \mu \mathrm{g} / \mathrm{ml})$ were prepared in methanol. Intermediate stock solutions of both analyte and internal standard $(10 \mu \mathrm{g} / \mathrm{ml})$ were prepared in diluent (50\% methanol in water) along with standard internal dilution $(40 \mathrm{ng} / \mathrm{ml})$. Nine level calibrators and four-level controls were prepared in human plasma containing sodium citrate as anticoagulant ranging from $1-250 \mathrm{ng} / \mathrm{ml}$ and $1-125 \mathrm{ng} / \mathrm{ml}$ respectively.

\section{Sample preparation}

$50 \mu \mathrm{l}$ of internal standard was added to $200 \mu \mathrm{l}$ pre-spiked plasma samples and $50 \mu \mathrm{l}$ of diluent has been added to the blank samples in prelabelled micro vials. Samples were vortexed to mix well. Samples were pretreated with $500 \mu \mathrm{l}$ of $0.10 \%$ orthophosphoric acid vortexed to mix. Apixaban and apixaban 13CD 3 were subjected to 
SPE using celerity deluxe (bed weight $30 \mathrm{mg}$, volume $1 \mathrm{ml}-\mathrm{DVB} \mathrm{LP}$ ) cartridges purchased from Orochem India Pvt Ltd., Cartridges were conditioned and equilibrated with $0.90 \mathrm{ml}$ of methanol followed by $0.90 \mathrm{ml}$ of water. Pretreated plasma samples were dispensed onto the cartridges and were washed with $0.90 \mathrm{ml}$ of water. Cartridges were allowed to dry under the stream of nitrogen gas and were washed with $0.90 \mathrm{ml}$ of $20 \%$ methanol in water (twice) before drying again. Analyte and internal standard were eluted with 0.75 $\mathrm{ml}$ of acetonitrile and the eluent was collected onto prelabelled HPLC vials. $10 \mu \mathrm{l}$ of the eluent from each sample was injected on the LC-MS/MS system.

\section{Instrumentation and analytical conditions}

Above mentioned extraction procedure was optimized during method development and it was validated using ultimate 3000 HPLC system interfaced with a TSQ Endura triple quadrupole mass spectrometer (Thermo Fisher Scientific Inc). Heated electrosprayionization source (HESI) was operated in the positive mode. Chromatographic separations were performed using a Hypersil beta basic C18 $(100 \times 4.6 \mathrm{~mm}$ inner diameter, $5 \mu$ particle size; Thermo Fisher Scientific Inc) at a column temperature of 40 ?. $2 \mathrm{mmol}$ ammonium acetate in water and acetonitrile were used as mobile phase in pump A and pump B respectively without premixing. Isocratic program conditions were optimized with the composition of phase A ranging from 50 to $20 \%$ out of which $20 \%$ phase A and $80 \%$ phase $\mathrm{B}$ gave optimal results at a flow rate of $0.50 \mathrm{ml} / \mathrm{min}$ without a splitter. Apixaban and apixaban 13C D3 were selectively resolved on the reverse phase column at 2.35 min with a total run time of $4.00 \mathrm{~min}$.

Optimized mass spectrometer parameters used for apixaban analysis were mentioned below: sheath gas 50 (arb), auxiliary gas pressure 25 (arb), capillary temperature $300{ }^{\circ} \mathrm{C}, \mathrm{Q} 2$ gas pressure $1.50 \mathrm{~m}$ Torr, ion spray voltage $3500 \mathrm{~V}$, and vaporizer temperature $300{ }^{\circ} \mathrm{C}$. Selected reaction monitoring (SRM) transitions for quantification were $\mathrm{m} / \mathrm{z} \quad 460.10 \rightarrow 443.05$ for apixaban and $464.22 \rightarrow 447.06$ for apixaban 13C D3 respectively. Representative chromatograms and a calibration curve of apixaban obtained during method validation are shown in fig. 2 and 3 :

\section{RT: 2.12}

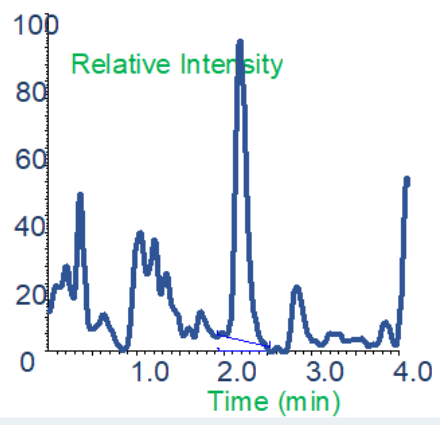

Extracted blank
$\mathrm{RT}: 2.12$

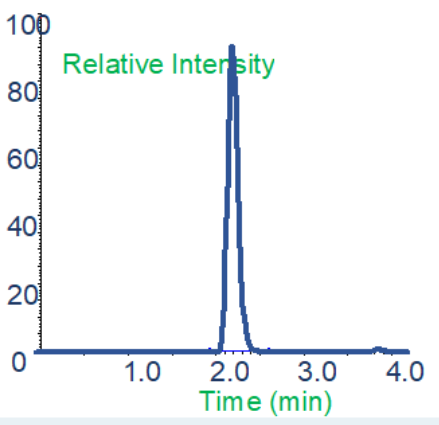

Extracted LLOQ

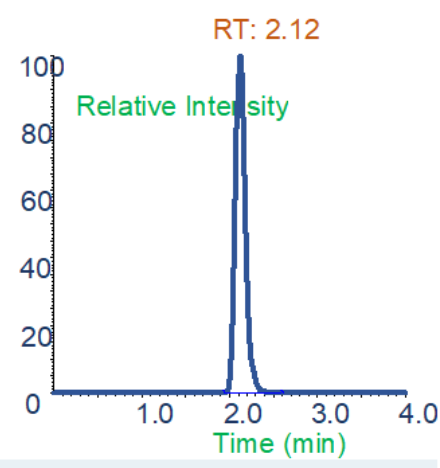

Extracted upper limit of quantification (ULOQ)

Fig. 2: Representative chromatograms of apixaban

APIXABAN

$Y=0.00427708+0.184256^{*} X \quad R^{\wedge} 2=0.9997 \quad W: 1 X^{\wedge} 2$

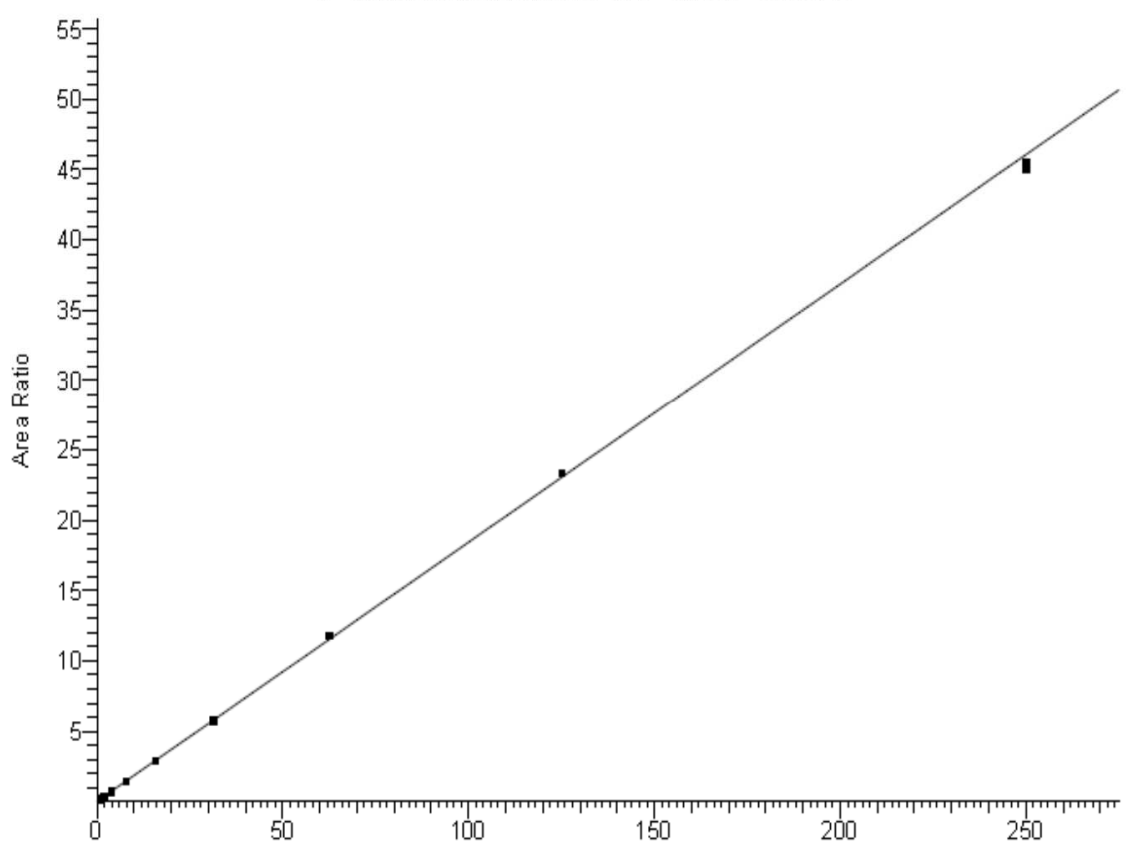

Fig. 3: Calibration curve of apixaban in human plasma from 1-250 ng/ml 


\section{RESULTS}

\section{Method validation}

During validation, the method has been validated for selectivity, linearity, precision and accuracy (PA), recovery and stability studies as per current United States food and drug administration (USFDA) recommendations [14].
5 Precision and accuracy batches (includes ruggedness and stability PA batch) were analyzed with the calibration curve ranging from 1$250 \mathrm{ng} / \mathrm{ml}$. A straight-line equation $(\mathrm{y}=\mathrm{mx}+\mathrm{c})$ with $1 / \mathrm{x}^{2}$ weighting factor has been used to quantify the back-calculated concentration of the calibrators and the coefficient of determination $\left(\mathrm{r}^{2}\right)$ was greater than 0.99 in all 5 batches. Summary of back-calculated concentrations and calibration curve parameters from all 5 PA batches were mentioned below in table 1-2.

Table 1: Precision and accuracy

\begin{tabular}{|c|c|c|c|c|c|c|c|c|c|}
\hline $\begin{array}{l}\text { Standard } \\
\text { name }\end{array}$ & CS-1 & CS-2 & CS-3 & CS-4 & CS-5 & CS-6 & CS-7 & CS-8 & CS-9 \\
\hline $\begin{array}{l}\text { Nominal } \\
\text { concentration } \\
(\mathrm{ng} / \mathrm{ml})\end{array}$ & 0.98 & 1.95 & 3.91 & 7.81 & 15.63 & 31.25 & 62.5 & 125 & 250 \\
\hline $\mathrm{P}$ and $\mathrm{A}-01$ & 0.98 & 1.91 & 3.91 & 7.81 & 15.66 & 13.3 & 64 & 126.8 & 249.56 \\
\hline $\mathrm{P}$ and $\mathrm{A}-02$ & 0.97 & 2.01 & 3.5 & 7.56 & 14.6 & 31.2 & 66.6 & 130.26 & 251.69 \\
\hline$P$ and $A-03$ & 1.02 & 2 & 3.99 & 8.01 & 16.52 & 33.25 & 60.53 & 125.03 & 255.33 \\
\hline $\mathrm{P}$ and $\mathrm{A}-04$ & 0.95 & 1.86 & 3.55 & 7.95 & 15.02 & 31.03 & 63.26 & 126.36 & 251.03 \\
\hline $\mathrm{P}$ and $\mathrm{A}-05$ & 1.1 & 1.99 & 3.86 & 8.01 & 14.96 & 30.13 & 60.24 & 124.57 & 248.6 \\
\hline mean $\pm S D$ & $1.00 \pm 0.06$ & $1.95 \pm 0.07$ & $3.76 \pm 0.22$ & $7.87 \pm 0.19$ & $15.35 \pm 0.76$ & $27.78 \pm 8.17$ & $62.92 \pm 2.63$ & $126.60 \pm 2.24$ & $251.24 \pm 2.59$ \\
\hline$\% \mathrm{CV}$ & 5.92 & 3.43 & 5.88 & 2.42 & 4.94 & 29.43 & 4.18 & 1.77 & 1.03 \\
\hline$\%$ Nominal & 102.78 & 100 & 96.26 & 100.73 & 98.25 & 88.9 & 100.68 & 101.28 & 100.5 \\
\hline
\end{tabular}

Mean statistical data are expressed as mean \pm SD $[n=5]$

Table 2: Calibration curve parameters summary

\begin{tabular}{llll}
\hline Result table ID & Slope & Y-Intercept & Regression coefficient [r'] \\
\hline P and A-01 & 0.0043 & 0.18 & 1.000 \\
P and A-02 & 0.0033 & 0.16 & 0.999 \\
P and A-03 & 0.0030 & 0.17 & 0.999 \\
P and A-04 & 0.0043 & 0.17 & 1.000 \\
STABILITY P and A & 0.0041 & 0.17 & 0.999 \\
\hline
\end{tabular}

Specificity and selectivity of the method were assessed in 6 different lots of human plasma containing sodium citrate as an anticoagulant. Hemolyzed and lipidemic (each lot) were also used for evaluation of selectivity of apixaban. \% interference in blank was found to be $0.89 \%$ when compared against the lower limit of quantification (LLOQ) area of apixaban. Results were presented below in table 3.

Table 3: Specificity and selectivity

\begin{tabular}{|c|c|c|c|c|c|c|}
\hline \multicolumn{4}{|l|}{ Apixaban } & \multicolumn{3}{|c|}{ Apixaban ${ }^{13}$ CD3 } \\
\hline Matrix Lot no & $\begin{array}{l}\text { Area in Blank } \\
\text { Matrix at analyte } \\
\text { RT }\end{array}$ & $\begin{array}{l}\text { Area of } \\
\text { LLOQ }\end{array}$ & $\begin{array}{l}\text { \%Interference at the } \\
\text { retention time of } \\
\text { Apixaban }\end{array}$ & $\begin{array}{l}\text { Area in Blank } \\
\text { Matrix at IS } \\
\text { RT }\end{array}$ & $\begin{array}{l}\text { Area of } \\
\text { LLOQ }\end{array}$ & $\begin{array}{l}\text { \% Interference at the } \\
\text { retention time of Apixaban } \\
13 \mathrm{CD} 3\end{array}$ \\
\hline LOT 1 & 872 & 84476 & 1.03 & 100 & 444921 & 0.02 \\
\hline LOT 2 & 649 & 86521 & 0.75 & 80 & 468670 & 0.02 \\
\hline LOT 3 & 573 & 85961 & 0.67 & 120 & 459203 & 0.03 \\
\hline LOT 4 & 921 & 88753 & 1.04 & 104 & 440031 & 0.02 \\
\hline LOT 5 & 953 & 92546 & 1.03 & 98 & 441722 & 0.02 \\
\hline LOT 6 & 687 & 95685 & 0.72 & 112 & 465281 & 0.02 \\
\hline $\begin{array}{l}\text { LOT } 7 \\
\text { (HEMOLYZED) }\end{array}$ & 1012 & 102346 & 0.99 & 150 & 445281 & 0.03 \\
\hline $\begin{array}{l}\text { LOT } 8 \\
\text { (LIPIDEMIC) }\end{array}$ & 986 & 110251 & 0.89 & 126 & 452281 & 0.03 \\
\hline
\end{tabular}

Intra-day precision and accuracy was evaluated in 6 replicates of quality control (QC) samples at LLOQ, low (LQC), middle (MQC) and higher (HQC) levels over one PA batch and was found to be between
0.78-1.03\% and 98.49-101.29 respectively over a range of 0.98-125 $\mathrm{ng} / \mathrm{ml}$. Intra-day precision and accuracy results were presented in table 4 .

Table 4: Intra-day precision and accuracy

\begin{tabular}{lllll}
\hline QC concentration & LLOQ QC & LQC & MQC & HQC \\
\hline & 0.98 & 3.95 & 31.25 & 125 \\
Mean \pm SD $(n=6)$ & $0.96 \pm 0.01$ & $3.89 \pm 0.03$ & $31.52 \pm 0.25$ & $126.61 \pm 1.10$ \\
\% CV & 1.03 & 0.85 & 0.78 & 0.87 \\
Nominal & 98.7 & 98.49 & 100.87 & 101.29 \\
\hline
\end{tabular}

Mean statistical data are expressed as mean $\pm \operatorname{SD}[n=6]$ 
Inter-day precision and accuracy experiments were evaluated in 4 batches at the same levels mentioned above and the results were found to be between 2.48-4.29\% and 97.72-102.36 \%, respectively. Results of Inter-day precision and accuracy were tabulated in table 5.

Table 5: Inter-day precision and accuracy

\begin{tabular}{|c|c|c|c|c|}
\hline QC & LLOQ QC & LQC & MQC & HQC \\
\hline Nominal concentration & 0.98 & 3.95 & 31.25 & 125 \\
\hline mean \pm SD $(n=24)$ & $0.95 \pm 0.03$ & $4.05 \pm 0.17$ & $31.50 \pm 1.02$ & $126.89 \pm 3.15$ \\
\hline$\% \mathrm{CV}$ & 2.67 & 4.29 & 3.25 & 2.48 \\
\hline$\%$ Nominal & 97.72 & 102.36 & 100.82 & 101.51 \\
\hline
\end{tabular}

Mean statistical data are expressed as mean \pm SD $[n=24]$

Matrix effect was studied for both apixaban and apixaban 13C D3 in eight lots of plasma ( 6 normal, 1 hemolyzed and 1 lipidemic plasma). Internal standard (IS) normalized matrix factor was calculated as a ratio of the response ratio of post extracted spiked sample upon aqueous sample at both HQC and LQC concentration levels and mean IS normalized matrix factor was found to be 1.00 .

Results of IS normalized matrix effect experiment were provided below in table 6 .

Table 6: Matrix effect experiment

\begin{tabular}{|c|c|c|c|c|c|c|c|}
\hline QC & $\begin{array}{l}\text { Response ratio of post } \\
\text { extracted spike sample }\end{array}$ & $\begin{array}{l}\text { Response ratio of } \\
\text { aqueous standard }\end{array}$ & $\begin{array}{l}\text { Matrix } \\
\text { factor }\end{array}$ & QC & $\begin{array}{l}\text { Response ratio of post } \\
\text { extracted spike sample }\end{array}$ & $\begin{array}{l}\text { Response ratio of } \\
\text { aqueous standard }\end{array}$ & $\begin{array}{l}\text { Matrix } \\
\text { factor }\end{array}$ \\
\hline \multirow{8}{*}{ LQC } & 0.190 & 0.189 & 1.004 & & 0.727 & 0.729 & 0.997 \\
\hline & 0.191 & 0.190 & 1.006 & & 0.717 & 0.707 & 1.014 \\
\hline & 0.188 & 0.190 & 0.990 & & 0.733 & 0.702 & 1.044 \\
\hline & 0.190 & 0.190 & 1.002 & HQC & 0.72 & 0.693 & 1.040 \\
\hline & 0.189 & 0.188 & 1.008 & & 0.694 & 0.727 & 0.955 \\
\hline & 0.190 & 0.188 & 1.014 & & 0.684 & 0.713 & 0.960 \\
\hline & 0.190 & 0.187 & 1.014 & & 0.722 & 0.724 & 0.997 \\
\hline & 0.190 & 0.190 & 0.998 & & 0.709 & 0.720 & 0.984 \\
\hline \multirow{2}{*}{\multicolumn{3}{|c|}{$\begin{array}{l}\text { Mean IS normalized matrix factor of LQC }[\text { mean } \pm \text { SD } \\
(\mathrm{n}=8)] \\
\% \mathrm{CV}\end{array}$}} & $1.00 \pm 0.01$ & \multirow{2}{*}{\multicolumn{3}{|c|}{$\begin{array}{l}\text { Mean IS normalized matrix factor of HQC [mean } \pm \text { SD } \\
(\mathrm{n}=8)] \\
\% \mathrm{CV}\end{array}$}} & $1.00 \pm 0.03$ \\
\hline & & & 0.8 & & & & 3.3 \\
\hline
\end{tabular}

Mean statistical data are expressed as mean \pm SD $[\mathrm{n}=8]$

Mean recovery of apixaban was obtained by calculating the response ratio of extracted and aqueous samples at LQC, MQC, HQC levels and was found to be $99.22 \%$ and $95.25 \%$ for apixaban and apixaban ${ }^{13} \mathrm{C}$ D3 respectively. Results of recovery experiment were presented in table 7 .

Table 7: Recovery of apixaban

\begin{tabular}{lll}
\hline QC & Response of extracted sample & Response of Unextracted sample \\
\hline LQC $(n=6)$ & 3291664 & 3322320 \\
MQC $(n=6)$ & 2468748 & 2491740 \\
HQC $(n=6)$ & 9874992 & 9966960 \\
Mean recovery (mean \pm SD) & \\
\% CV & & 99.03 \\
\hline
\end{tabular}

Mean statistical data are expressed as mean $\pm \mathrm{SD}[\mathrm{n}=6 \times 3]$

Stability experiments in the biological matrix were conducted for bench top $(10.0 \mathrm{~h})$, freeze-thaw $4^{\text {th }}$ cycle (at-50 ${ }^{\circ} \mathrm{C}$ and at-20 ${ }^{\circ} \mathrm{C}$ ), auto-sampler (48 h), wet extract ( $32 \mathrm{~h} 30 \mathrm{~min})$ and long-term storage (at-50 ${ }^{\circ} \mathrm{C}$ ) and results were mentioned below in table 8-9

Table 8: Stability experiments in biological matrix

\begin{tabular}{|c|c|c|c|}
\hline Comparison QC details & Mean \pm SD $(n=6)$ & $\% \mathrm{CV}$ & \% Nominal \\
\hline Freshly spiked LQC & $4.12 \pm 0.16$ & 3.91 & 103.97 \\
\hline Freshly spiked HQC & $125.95 \pm 4.83$ & 3.83 & 100.75 \\
\hline Stability QC details & mean \pm SD $(n=6)$ & $\% \mathrm{CV}$ & \% Nominal \\
\hline Autosampler stability-LQC (48 h) & $4.25 \pm 0.25$ & 5.78 & 107.38 \\
\hline Autosampler stability-HQC (48 h) & $128.54 \pm 2.13$ & 1.66 & 102.82 \\
\hline FT 4th Cycle LQC $\left(-50^{\circ} \mathrm{C}\right)$ & $4.14 \pm 0.16$ & 3.86 & 104.6 \\
\hline FT 4 th Cycle HQC $\left(-50^{\circ} \mathrm{C}\right)$ & $133.27 \pm 2.90$ & 2.18 & 106.61 \\
\hline FT 4th Cycle LQC $\left(-20^{\circ} \mathrm{C}\right)$ & $4.22 \pm 0.16$ & 3.84 & 106.43 \\
\hline FT 4th Cycle HQC $\left(-20^{\circ} \mathrm{C}\right)$ & $133.22 \pm 3.00$ & 2.25 & 106.56 \\
\hline Wet extract stability LQC (32 h $30 \mathrm{~min})$ & $3.90 \pm 0.10$ & 2.6 & 98.38 \\
\hline Wet extract stability HQC ( 32 h $30 \mathrm{~min})$ & $126.94 \pm 2.77$ & 2.18 & 101.54 \\
\hline Bench top stability (LQC) $(10 \mathrm{~h})$ & $3.60 \pm 0.33$ & 9.08 & 90.74 \\
\hline Bench top stability (HQC) $(10 \mathrm{~h})$ & $139.27 \pm 9.77$ & 7.01 & 111.41 \\
\hline
\end{tabular}

Mean statistical data are expressed as mean $\pm S D[n=6]$ 
Table 9: Long term matrix stability

\begin{tabular}{|c|c|c|c|}
\hline Comparision QC details & Mean \pm SD $(n=6)$ & $\% \mathrm{CV}$ & $\%$ Nominal \\
\hline Freshly spiked LQC & $3.95 \pm 0.12$ & 3.15 & 99.58 \\
\hline Freshly spiked HQC & $132.31 \pm 9.28$ & 7.01 & 105.84 \\
\hline Stability QC details & mean \pm SD $(n=6)$ & $\% \mathrm{CV}$ & \% Nominal \\
\hline LTMS LQC-100 d & $3.42 \pm 0.31$ & 9.08 & 86.2 \\
\hline LTMS HQC-100 d & $119.65 \pm 4.59$ & 3.83 & 95.71 \\
\hline
\end{tabular}

Mean statistical data are expressed as mean \pm SD $[n=6]$

Sensitivity (Limit of detection or LOD) was performed by injecting six replicates of the extracted sample prepared at a concentration of $50 \mathrm{pg} / \mathrm{ml}$ under the same chromatographic conditions and the results were found to be accurate and precise. Summarized data of the experiment is presented in table 10 .

Table 10: Limit of detection

\begin{tabular}{|c|c|c|c|}
\hline Actual concentration of LOD & Mean concentration-pg/ml [mean \pm SD $(n=6)]$ & $\% \mathrm{CV}$ & \% Nominal \\
\hline $50 \mathrm{pg} / \mathrm{ml}(\mathrm{n}=6)$ & $47.88 \pm 1.83$ & 3.83 & 95.77 \\
\hline
\end{tabular}

Mean statistical data are expressed as mean \pm SD $[n=6]$

Reinjection reproducibility was evaluated by re-injecting the entire PA batch, which was earlier subjected to analysis. Samples were kept in autosampler for $26 \mathrm{~h} 30$ min before subjecting the samples for reinjection. Results were provided below in table 11 .

Table 11: Reinjection reproducibility

\begin{tabular}{llll}
\hline Sample name & Mean \pm SD (n=6) & \% CV & \% Nominal \\
\hline LLOQ QC $0.98 ~ p g / m l$ & $0.93 \pm 0.06$ & 6.31 & 3.68 \\
LQC 3.95 pg/ml & $4.12 \pm 0.15$ & 4.14 & 104.22 \\
MQC $31.25 \mathrm{pg} / \mathrm{ml}$ & $32.41 \pm 1.34$ & 103.71 \\
HQC $125.00 \mathrm{pg} / \mathrm{ml}$ & $125.76 \pm 2.00$ & 1.59 & 100.61 \\
\hline
\end{tabular}

Mean statistical data are expressed as mean \pm SD $[n=6]$

Dilution integrity was checked in the dilution quality control sample diluted up to 2 and 5 times respectively. Samples were processed under freshly prepared calibration curve standards. Results of the dilution integrity experiment were presented below in table 12.

Table 12: Dilution integrity

\begin{tabular}{lll}
\hline Dilution integrity & Dilution factor: $\mathbf{2}$ concentration & Dilution Factor: 5 concentration \\
\cline { 2 - 3 } & $\mathbf{3 7 5}$ & $\mathbf{3 7 5}$ \\
\cline { 2 - 3 } & $\mathbf{0 b s e r v e d ~ c o n c e n t r a t i o n ~} \mathbf{n g} / \mathbf{m l})$ & $365.46 \pm 12.83$ \\
\hline mean \pm SD $(\mathrm{n}=6)$ & $374.35 \pm 3.75$ & 3.51 \\
\% CV & 1 & 97.46 \\
\hline
\end{tabular}

Mean statistical data are expressed as mean \pm SD [n=6], Ruggedness experiment was performed by injecting a freshly prepared PA batch on a different column. Results of the experiment were provided below in table 13 .

Table 13: Ruggedness

\begin{tabular}{|c|c|c|c|c|}
\hline \multirow[t]{2}{*}{ QC concentration } & LLOQ QC & LQC & MQC & HQC \\
\hline & 0.95 & 4.11 & 31.13 & 126.43 \\
\hline mean $\pm S D(n=6)$ & $0.03 \pm 3.30$ & $0.04 \pm 0.89$ & $1.49 \pm 4.77$ & $3.11 \pm 2.46$ \\
\hline$\% \mathrm{CV}$ & 97.56 & 104.09 & 99.61 & 101.14 \\
\hline$\%$ Nominal & 0.95 & 4.11 & 31.13 & 126.43 \\
\hline
\end{tabular}

Mean statistical data are expressed as mean $\pm \operatorname{SD}[\mathrm{n}=6]$

\section{DISCUSSION}

The current study has been successfully validated as per USFDA guidelines [14]. Validation parameters and acceptance criteria of the results are mentioned below in table 14 where the requirements for assessment of the data has been clearly defined. 
Table 14: Validation parameters and their acceptance criteria

\begin{tabular}{|c|c|c|}
\hline S. No. & Parameter & Acceptance criteria \\
\hline \multirow[t]{6}{*}{1} & Linearity & Minimum 5-point standards are required for building a calibration curve \\
\hline & (includes & Two consecutive standards should not fail \\
\hline & ruggedness and & First and last calibration standard should not fail \\
\hline & stability) & At least $75 \%$ of the calibration curve standards should be with the acceptable limits for accuracy and precision \\
\hline & & $\%$ Accuracy and precision should be within $85-115 \%$ for all standards except LLOQ QC. \\
\hline & & $\%$ Accuracy and precision should be within $80-120 \%$ for LLOQ QC \\
\hline \multirow[t]{4}{*}{2} & PA [(inter-day & $\%$ Accuracy and precision should be within $85-115 \%$ for all QCs except LOQ QC. \\
\hline & and intra-day) & $\%$ Accuracy and precision should be within $80-120 \%$ for LOQ QC. \\
\hline & and (stability & At least $67 \%$ of the quality control samples should be within specified criteria for precision and accuracy \\
\hline & studies)] & At least $50 \%$ quality control samples should meet the criteria specified for accuracy and precision \\
\hline \multirow[t]{2}{*}{3} & $\begin{array}{l}\text { Specificity and } \\
\text { selectivity }\end{array}$ & $\begin{array}{l}\% \text { interference at the retention time of the analyte in the blank sample should not be more than } 20 \% \text { of the peak area } \\
\text { of analyte }\end{array}$ \\
\hline & & $\begin{array}{l}\% \text { interference at the retention time of the internal standard in the blank sample should not be more than } 5 \% \text { of the } \\
\text { peak area of the internal standard }\end{array}$ \\
\hline 4 & Matrix effect & Mean matrix factor and is normalized matrix factor should be between $0.85-1.15$ \\
\hline 5 & Recovery & $\begin{array}{l}\text { No as such criteria defined for \% recovery. The precision obtained for mean and global recovery should be with } \\
\text { in } \pm 15 \%\end{array}$ \\
\hline 6 & $\begin{array}{l}\text { Dilution integrity } \\
\text { (DI) }\end{array}$ & Precision and accuracy of the DI QCs should be within $85-115 \%$ \\
\hline 7 & $\begin{array}{l}\text { Limit of detection } \\
\text { (LOD) }\end{array}$ & Precision and accuracy of the sensitivity samples should be within 85-115 \% \\
\hline
\end{tabular}

On the basis of the results obtained, all experiments were found to be within acceptance criteria that were defined above in table 14 . While assessing the linearity of the calibration curves, \% nominal of the standard concentrations was found to be between 88.91 to 102.78. Linearity study results were given in table 1-2. Inter-day and intra-day QC data were tabulated in table 4-5 and the data represented do not contain any outliers. Method was found to be more selective and specific, without any matrix effect and the results were presented in table 3 and 6 . Mean extraction recoveries were found to be $99.22 \pm 0.24$ and the results were given in table 7 .

During method comparison, it was observed that only few methods employed a single step sample extraction $[2,5,10,12]$ by using protein precipitation. But protein precipitation is not preferred by many due to improper sample cleanup. Techniques like turbulent flow liquid chromatography with high-resolution mass spectrometry was used [11], but the setup requires highly skilled manpower and it is a costly setup. The current method was developed and validated by using a simple and single-step solid phase extraction procedure which is relatively costeffective, highly specific and sensitive. Further sensitivity of the method was successfully evaluated till the lowest detection level i.e., $50 \mathrm{pg} / \mathrm{ml}$, whereas the limit of detection in the reported literatures [2-13] is not less than $1 \mathrm{ng} / \mathrm{ml}$. Results of LOD were presented in table 10.

\section{CONCLUSION}

The developed method is highly sensitive, selective and it is a key differentiator with a LOD of $50 \mathrm{pg} / \mathrm{ml}$ employing just $200 \mu \mathrm{l}$ of the plasma sample. This was achieved due to the proper cleanup of the samples using a single-step solid-phase extraction of acidified plasma samples. With the ability to analyze over 360 samples per day this method is not only suitable for PK study analysis but can be validated and used for TDM also provided, the sample quantity must be further reduced as the single sample in clinical diagnostics is required for performing many other additional tests. This kind of method transfer is possible as a recent study [12] conducted on a set of blood samples from 116 patients treated with new oral anticoagulant reveals that "the results of both specific dilute thrombin time (dTT) tests for dabigatran provided the same results as the activated partial thromboplastin time (aPTT) screening test in comparison with LC-MS/MS as a reference." The results of both specific dTT tests for dabigatran provided the same results as the activated partial thromboplastin time aPTT screening test in comparison with LC-MS/MS as a reference. Hence, the objective of the current research work is fulfilled as it can be applied to conduct PK study analysis as well as TDM.

\section{AUTHORS CONTRIBUTIONS}

Dr. Cheepurupalli Prasad and Rajaram S Patil were involved in supervision and guidance of the proposed research work. Chaitanya Krishna Atmakuri is involved in the design, development and implementation of the current research work. Dr. Karunakranth Dharani played his role as an expert advisor for the current research work.

\section{CONFLICT OF INTERESTS}

We wish to confirm that there are no known conflicts of interest associated with this publication and there has been no significant financial support for this work that could have influenced its outcome

\section{REFERENCES}

1. Tyler Hall. Oral anticoagulants: considerations for the use of warfarin, apixaban and rivaroxaban. Formulary flash 2017;17:1-4.

2. Charles Frost, Sunil Nepal, Jessie Wang, Alan Schuster, Wonkyung Byon, Rebecca A Boyd, et al. Safety, pharmacokinetics and pharmacodynamics of multiple oral doses of apixaban, a factor Xa inhibitor, in healthy subjects. Br J Clin Pharmacol 2013;76:776-86.

3. Wan-li Zhang, Dan Lou, Dong-Tao Zhang, Yin Zhang, Huan-Jie Huang. Determination of rivaroxaban, apixaban and edoxaban in rat plasma by UPLC-MS/MS method. J Thromb Thrombolysis 2016;42:205-11.

4. Sofia Lindahl, Roar Dyrkorn, Olav Spigset, Solfrid Hegstad. Quantification of apixaban, dabigatran, edoxaban, and rivaroxaban in human serum by UHPLC-MS/MS-method development, validation, and application. Ther Drug Monit 2018;40:369-76.

5. Ludek Slavik, Jiri Lukes, David Friedecky, Monika Zhanelova, Marketa Nemcova, Jana Ulehlova, et al. Multianalyte determination of NOACs using LC-MS/MS and comparison with functional coagulation assays. Clin Lab (Mainz, Ger) 2018;64:1611-21.

6. Sara Baldelli, Dario Cattaneo, Pasquale Pignatelli, Valentina Perrone, Daniele Pastori, Sonia Radice, et al. Validation of an LC-MS/MS method for the simultaneous quantification of dabigatran, rivaroxaban and apixaban in human plasma. Bioanalysis 2016;8:275-83.

7. Janice Pursley, Jim X Shen, Alan Schuster, Oanh T Dang, Jim Lehman, Michael H Buonarati, et al. LC-MS/MS determination of apixaban (BMS-562247) and its major metabolite in human plasma: an application of polarity switching and monolithic HPLC column. Bioanalysis 2014;6:2071-82. 
8. Mirza Layeeq Ahmed Baig, Syed Ayaz Ali. A validated LCMS/MS method for the estimation of apixaban in human plasma. J Appl Pharm Sci 2017;7:44-52.

9. Blaich C, Müller C, Michels G, Wiesen MH. Multi-analyte analysis of non-vitamin $\mathrm{K}$ antagonist oral anticoagulants in human plasma using tandem mass spectrometry. Clin Chem Lab Med 2015;53:1981-90.

10. Delavenne X, Mismetti P, Basset T. Rapid determination of apixaban concentration in human plasma by liquid chromatography/tandem mass spectrometry: application to pharmacokinetic study. J Pharm Biomed Anal 2013;7879:150-3.

11. Gous T, Couchman L, Patel JP, Paradzai C, Arya R, Flanagan RJ. Measurement of the direct oral anticoagulants apixaban, dabigatran, edoxaban, and rivaroxaban in human plasma using turbulent flow liquid chromatography with high-resolution mass spectrometry. Ther Drug Monit 2014;36:597-605.

12. Schmitz EM, Boonen K, Van den Heuvel DJ, Van Dongen JL, Schellings MW, Emmen JM, et al. Determination of dabigatran, rivaroxaban and apixaban by ultra-performance liquid chromatography-tandem mass spectrometry (UPLC-MS/MS) and coagulation assays for therapy monitoring of novel direct oral anticoagulants. J Thromb Haemostasis 2014;12:1636-46.

13. Tilea Ioan, Popa Daniela Saveta, Timea Szakacs, Primejdie Daniela, Grigorescu Bianca, Tilea Brindusa, et al. Determination of apixaban levels in human plasma by a high-throughput liquid chromatographic tandem mass spectrometry assay. Romanian J Laboratory Med 2015;23:115-26.

14. U.S. Food and Drug Administration. Bioanalytical Method Validation, Guidance for Industry. U. S. department of Health and Human Services Food and Drug Administration; 2018. p. 1-41. 